\title{
Architectural and ecological integration of postindustrial landscapes revitalization into socially oriented space of the embankment
}

\author{
Nina Ivanova ${ }^{1, *}$, Olga Ganzha ${ }^{1}$, Vyacheslav Prokopenko ${ }^{1}$ and Alexandra Artyukhina ${ }^{1}$ \\ ${ }^{1}$ Volgograd State Technical University, 28 Lenin avenue, 400005, Volgograd, Russia
}

\begin{abstract}
The architectural and ecological model of civil engineering of socially oriented spaces of coastal landscape aimed at providing comfortable vital environment, development of the greatest possible variety of city activities, solution of environmental and social problems of the city, and development of the embankment as a self-valuable fragment of wellarranged natural landscape is substantiated. The research objective is the development of methodical bases for the process of architectural revitalization of postindustrial coastal landscape. The researchers utilize the methods of system analysis, reviewing of design practice, analysis of available scientific databases as well as referential and normative resources. The methods of modeling and experimental projecting were also used in the study. Architectural proposals on integration of the revitalized postindustrial coastal areas into socially oriented area of the Volgograd embankment are presented. The analysis of the experience in building and recovery of postindustrial landscapes of river basins is preformed to substantiate the proposed architectural and ecological principles of revitalization, "tree of properties" with the definition of environment quality indicator, the sequence of stages in planning of socially oriented area of the city embankment, and experimental project on integration of the studied coastal area into the vital space of the city of Volgograd.
\end{abstract}

\section{Introduction}

The urban areas located near the rivers form the coastal spaces which historically had different functional planning. While in the XIX- the first half of the XX century the coastal territories were mostly built up with industrial facilities, at the beginning of the XXI century, the environmental and functional requirements as well as the social role of the spaces were reconsidered. Since then, revitalization as the return of coastal postindustrial territories to life was considered in terms of their architectural, ecological and landscape organization. As specialists note, in the 21st century evolution of coastal territories occurs on the basis of expansion of their functional saturation and variability of functional interaction [1]. Creation of recreational zones, new embankments on the site of postindustrial territories for the purpose of preservation of originality, authenticity, identity and historical resources of the

\footnotetext{
* Corresponding author: ivanovaninav@mail.ru
} 
urban environment is widely applied in the theory and world practice of architectural activity [2]. Extent of abandoned industrial complexes revitalization into living premises - lofts, museums, business centers and educational institutions depends on the degree of value of the historical and cultural objects $[3,4]$.

In many coastal Russian cities reconstruction of industrial territories is one of the main directions of the urban areas development. The closed industrial enterprises are located along the coastline on hundreds of hectares that allows functional planning of the area (to increase the distance between residential buildings, to allocate spaces for parks, boulevards and recreational zones, to place the necessary infrastructure facilities and to provide communication with the water object). Originally, industrial enterprises were located on the periphery of the urban development; now they appear in close proximity to the center. Withdrawal of the territory allows planning new housing even on the site which is completely built up. Industrial areas are also provided with good access roads to the main transportation routes and quays. The plants which are historically located along the Volga River (exit to water for the organization of cargo transportation, use of large amount of water for technical needs) [5] provide an example of the traditionally planned ? enterprises. Reconstruction of the coastline with manufacture premises has affected industrial areas of many countries. As an example, warehouses and loading platforms are placed at the territory of the former port of Rambo in Lyon (France). The process of transformation of industrial landscape in Turin (Italy) was aimed at creation of new harmonious landscape while preserving the original structure, symbolizing the ecology of the natural and technological systems [6,7].

Relevance of the study is substantiated by the development of architectural and ecological proposals on the formation of the socially oriented city embankment on the basis of the obtained results (quality indicator of visual perception of the coastal environment) and modeling of the urban environment in the revitalized area.

The scientific importance of the conducted research is proved by development of methodical bases for the architectural and ecological planning of postindustrial territories revitalization aimed at comfortable environment planning for citizens, modeling of socially oriented space for various activities and rest as well as improvement of the coastal area image and integration of the considered landscapes into the city life.

The study was based on practical and theoretical findings of scientific researches in the following areas:

- the European and Russian experience in revitalization of coastal territory [1 - 7];

- aspects of ecological perception of the volume and space composition of residential units, industrial building $[8,9]$, and the aspects of visual ecology determining the effects of air pollution [10-12];

- the role of color and its influence on the perception of the buildings' visage; coloring of the urban environment and search of reference space [13-16];

- space orientation in the environment ("orientation framework") [17-19];

- topical issues of domestic and foreign formation of complexes on embankments and processes of arrangement and reconstruction coastal territories (features of functioning, specifics of the architectural organization, condition of interaction of water resource and space structure of the building, pattern of design of the adjacent territory) are considered [20 - 27].

\section{Statement of a problem}

The coastal territory of the central part of Volgograd can be an example of the revitalization of riverside territory in terms of its historical development. At the moment, the length of the city is more than $90 \mathrm{~km}$ along the Volga, which determined the orientation of the main longitudinal roads and the formation of cross streets ("exits" to the river). Historically, the 
coast was filled with factory territories, ports, and piers alternating with residential quarters and sections of the city's network of gullies and draws. Formation of the coastal landscape of the city began in the 19th century, when Tsaritsyn began to settle at the intersection of trade routes, and the local port took first place in transportation in Russia (timber, coal, fish, metal, melons). The first attempts to improve the upper terrace date back to the beginning of the 20th century (slight slopes were improved, acacia trees were planted, a wooden staircase was built to the quays, and a place for public walks by the water was organized). In 1952, the first stage of reconstruction for the organization of a public space between the city and water with a ceremonial embankment in the Central district was completed (author is the People's Architect of the USSR V. Simbirtsev). Further revitalization of the post-industrial landscapes of the Volga basin is aimed at removing the industry from the shoreline and organizing a unified socially oriented space of embankment.

The objectives of the study were:

- study of domestic and foreign experience in the construction of coastal space;

- determination of the quality index of the urban coastal environment;

- formation of a model of socially oriented space with the sections of revitalization of post-industrial territories;

- verification of the results obtained in experimental design with the development of a system of basic modeling tasks.

The design base for the study was a section of the Central embankment of Volgograd in the Central district with existing residential buildings of different periods, public facilities, and open landscaped spaces of the Voroshilovsky district with the territory of the former cargo port, Fig. 1.

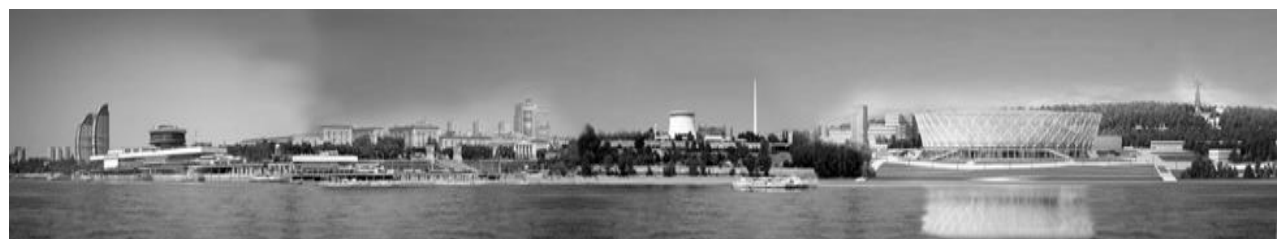

Fig. 1. Panorama of the coastal development of the city of Volgograd.

\section{Theoretical part}

The purpose of the study is to develop methodological foundations for organizing socially oriented spaces in the process of revitalization of the post-industrial riverside landscape in the concept of architectural and ecological approaches to the development of the public urban embankment.

The choice of practical solutions for landscape and ecological development of coastal territories depends on the mode of their use. In this case, regardless of the condition of the water body and the adjacent territory of the natural region, the main requirement for its rehabilitation is the fulfillment of the following conditions: maximum preservation of the biological corridor effect and maintenance of the ecosystem. The principles of the functional organization of the coastal territory are:

- functional zoning of coastal territories is carried out taking into account their location in the structure on the basis of the proposed models and upon condition of the keeping the priority of the recreational function based on the load and the value of the coastal landscape;

- the nature of the location of functions is determined by the remoteness of coastal territories from the water's edge (100-, 300-, 500-meter zones from the water's edge);

- the zoning of coastal territories depends on the nature of the water area and the spatial relationship with the city and its surroundings; 
- development of coastal territories is based on the principles of continuity, multiple-level system, uniformity of distribution of functions;

- for coastal zones of each type (central, middle, peripheral), an indicative balance of residential, public, and recreational areas is established [30].

The spatial and planning structure of post-industrial, disturbed, degraded, or ineffectively used territories of cities is currently one of the trends in urban regeneration of cities. One should not neglect the ecological component in the development of rapidly developing new forms of spaces. The quality of the environment of public spaces should be determined by a variety of indicators: convenience, multitasking, aesthetics, environmental friendliness, which characterizes it as a comfortable and accessible environment.

In the context of a landscape urban environment, a structural model is considered that allows identifying factors in the formation of socially oriented spaces in the planning structure of the city: architectural and ecological and ecological and aesthetic [1], Fig.2.

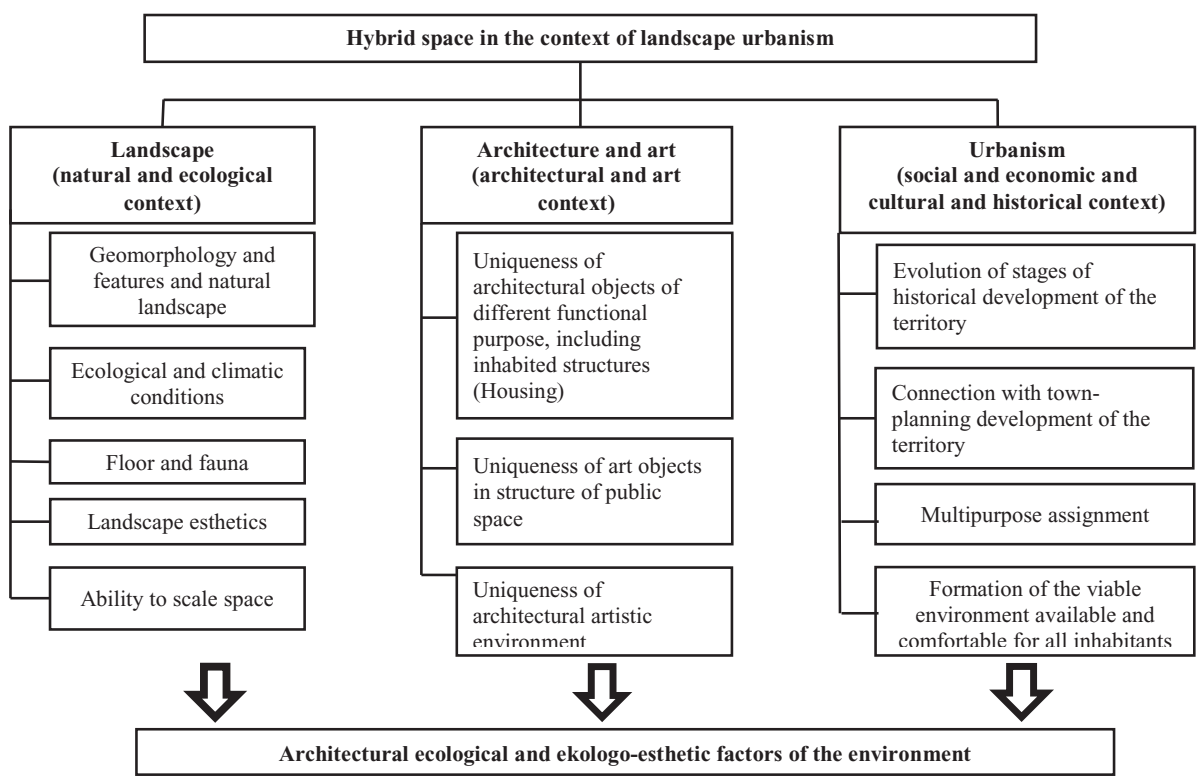

Fig. 2. Structural model of formation of socially oriented space taking into account environmental quality.

In order to conduct an environmental quality assessment, a method for constructing a "tree of properties" is proposed. 


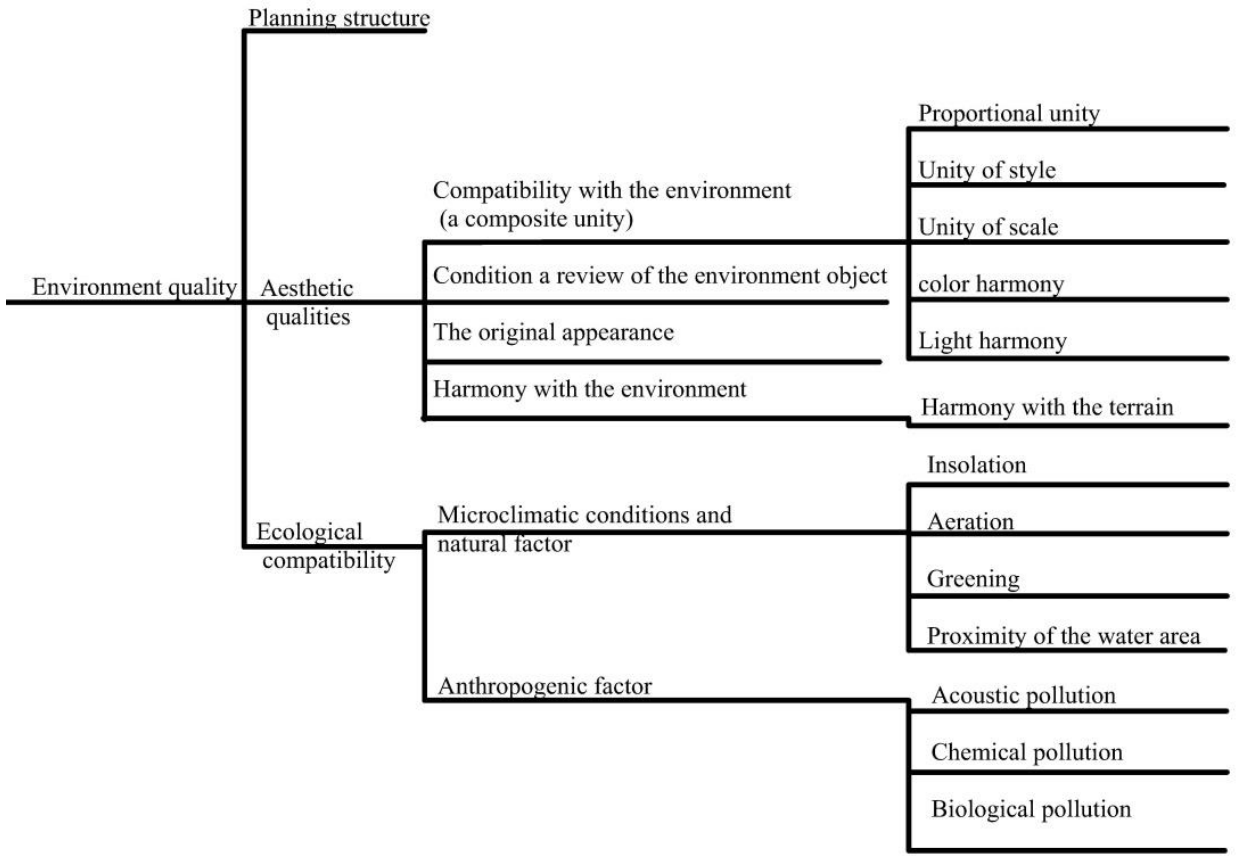

Fig. 3. Hierarchical structure - "tree of properties" that allows carrying out environmental quality assessment.

The tasks of planning the revitalization of the post-industrial part of the coastal territory were to study the feasibility of designing socially oriented development, i.e. integrating the developing coastal zone into urban life and creating the widest possible variety of urban activities. Such an approach capitalizes the territory under the study, which is not attractive, and can develop it as a valuable fragment of the landscaped natural landscape of the river basin.

Allocation in the coastal zone of public facilities that form socially oriented spaces acquires in Volgograd a number of features in the architectural and ecological interaction with the water resource and the conditions for revitalizing the coastal line. Characteristics of identification and expressiveness are new zones of urban events (presentations, exhibitions), objects of contacts (park, public gardens, squares, pedestrian streets); reference planning nodes of different functional purpose (Central staircase with Propylaeas, walking terraces, interactive park-museum "Russia is My History", and a bridge across the Volga River; sports destination - the territory and the architectural volume of the Volgograd-Arena stadium). The strategy of revitalization includes the expansion and continuity of urban public functions (beaches, water clubs, boat stations), infrastructure of leisure, sports, daily needs and services; security and orientation in space. It becomes important to solve environmental issues (comfortable conditions of movement, connection with the general system of landscaping), [31], Fig. 4. 

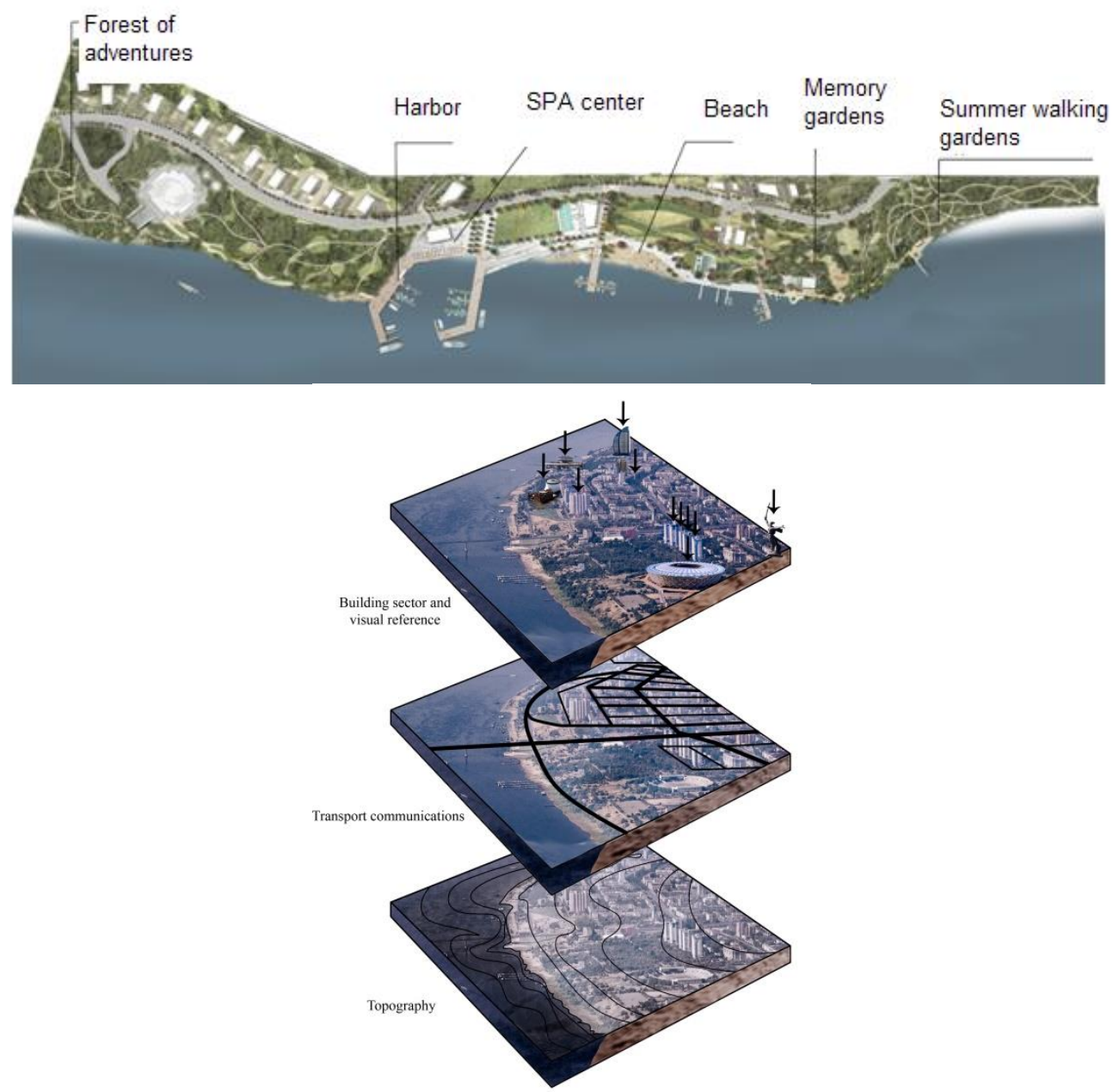

Fig. 4. Design of socially oriented spaces of the embankment, Volgograd.

\section{Practical significance, proposals and results of implementation, the results of experimental studies}

The practical significance of the work lies in the conducted analysis of the planning structure of the embankments of Volgograd, the coastal territory of the cargo port, the identification of the need to remove buildings and structures of industrial production outside the city limits, to reveal the potential of coastal zones in the city structure, and to improve the environment.

The result of the implementation was the development of a "model for the formation of a socially oriented space taking into account the quality of the environment" to determine the comfort indicators of riverside cities and the embankment section. The main tasks of integrated reclamation and the concept of territory development were: the formation of a new approach to the design of public embankment zones, which could determine the strategy for the development of the urban environment; the identification of space and spatial and architectural and planning solutions that combine high functionality, economic and energy 
efficiency; development of the main transport route along the river as a system of multifunctional communications (urban route, promenade, bicycle paths, parking lots). [32].

The result of the experimental study is manifested in the systematization of the content of socially oriented spaces when integrating coastal space into the life of Volgograd, planning the revitalization of former industrial zones, and the effective organization of coastal territory to ensure a high level of vital activity of citizens and the formation of an accessible environment for the people with limited mobility [33]. Revitalization of the territory of the former cargo port of Volgograd will improve the quality of the environment, minimize the appearance of negative anthropogenic impacts, activate the functionality of urbanized spaces, and ensure the aesthetics of riverside territory, Fig. 5.

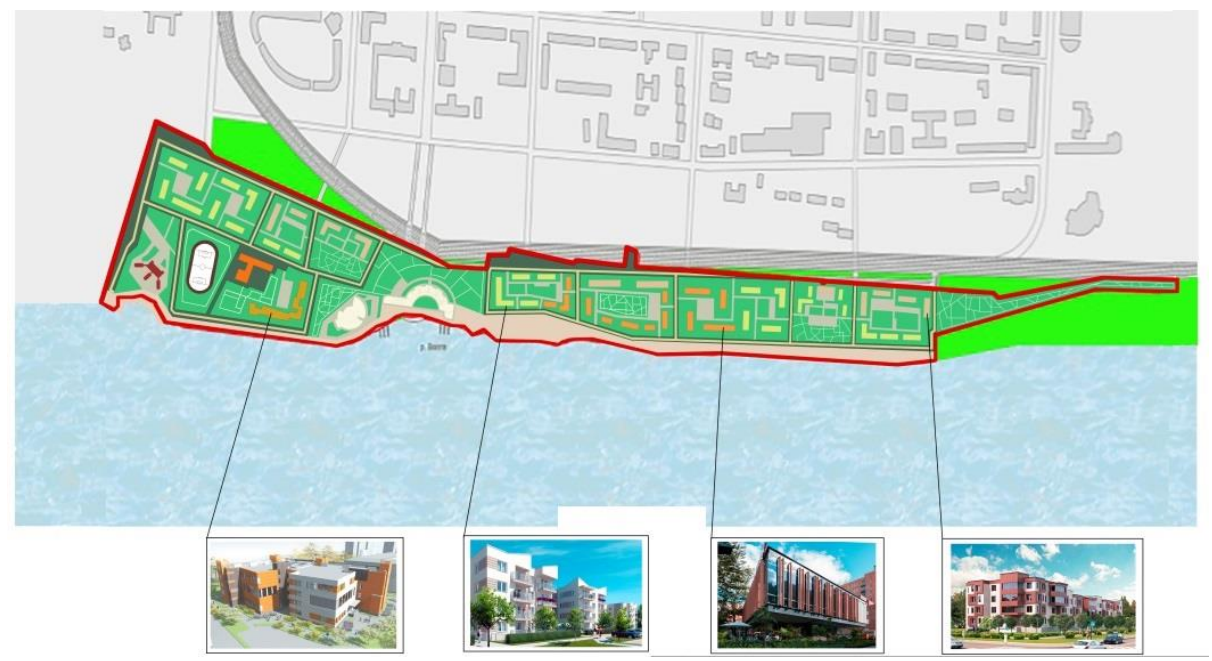

Fig. 5. Revitalization of the landscape of the former cargo port of Volgograd.

The principles of formation of harmonious socially oriented territory of the former cargo port and balance of various functions (business district, residential and recreational zones) are developed:

- providing connection of coastal territory with existing large objects of the city's natural complex and designing a unified system of sustainable landscaping of urban areas;

- division of coastal territory into plots with various functional purposes with the design of adaptive green plantations and compositional connections with the water area;

- restoration of immediate access zones to the shoreline and visual contact with the river;

- using the possibilities of man-made and natural relief of the coastal landscape for the formation of recreation areas, construction of built-in buildings [34, p.1009].

The main objective of the project was achieved: to integrate the territory of the former industrial river node for the development of a socially oriented landscape into the life of the city of Volgograd; to create the widest possible variety of urban activities; to ensure environmental safety of the environment and the water area of the Volga River basin.

\section{Conclusions}

Analysis of the experience of the revitalization of post-industrial zones made it possible to propose architectural and ecological design principles, "models for the formation of a socially oriented space" with the definition of the quality index of the environment, the types and sequence of stages in the formation of socially oriented spaces in the landscape of the city's embankment. 
The developed model of civil construction of socially oriented spaces becomes a tool for assessing the comfort of the social environment of the embankment and architectural and ecological initiatives. Successful implementation of the strategy of revitalization of the postindustrial landscapes of the Volga basin allows using the received proposals in domestic and foreign construction in similar natural and urban conditions.

\section{References}

1. E. Krasilnikova, D. Klimov, Balkan Architectural Biennale, Conference proceedings of "capitala", Belgrade: BAB 21-40 (2015)

2. A.A. Barabanov, Eco-potential 3-4, 237- 24 (2013)

3. E. Vladimirova, Building, rcmm.ru/pozdravleniya/26351

4. E.V. Demidov, J. Academic messenger Uralniiproyekt 1, 8-13 (2013)

5. New view on the old plants of $5 \mathbf{1 6 8}$, http://its.grandsmeta.ru/officially/5981/

6. Post-industrial landscapes, http://www.vashsad.ua/landscapedesign/interesting_plants /articles/show/9865

7. Post-industrial landscapes, http://www.vashsad.ua/landscapedesign/interesting_plants/articles/show/9858/

8. V.V. Aurov, M.D. Bausheva, E.V. Ulyanova, J. Scientific and publishing center Akademichesky 1-8 (2016)

9. Y.V. Skripkina, J. News of Southwest state university 5(68), 77-82 (2016)

10. A.A. Kuzmichev, V.N. Azarov, J. Biospheric compatibility: person, region, technologies 1(13), 86-96 (2016)

11. V.V. Fedorov, M.A. Fedorov, A.V. Levikov, J. Urgent problems of health and safety and ecology, 341-345 (2017)

12. O.N. Vorontsova, J. University complex as regional center of education, science and culture 10, 647-653 (2017)

13. M.Y. Sidorenko, J. Science UYrGU 5, 248-251 (2014)

14. A.A. Kokina, K.A. Lapunov, J. Scientific almanac 4-2 (30), 319-322 (2017)

15. E.A. Kolchin, B.A. Ivanov, D.B. Tnaliyeva, J. International magazine of humanitarian and natural sciences 1, 115-117 (2016)

16. N.E. Ivanovskaya, J. Architecture, town planning and design 13, 21-26 (2017)

17. N.V. Kupchikova, J. Perspectives of development of construction complex 1, 254-257 (2015)

18. O.V. Elkina, J. Scientific magazine of construction and architecture 2 (42), 110 (2016)

19. S.A. Kolesnikov, J. Town planning and architecture 2 (27), 114-118 (2017)

20. L.V. Gaykova, J. Architecture and Modern Information Technologies 1(42), 254-268 (2018)

21. K.A. Popravko, R.E. Tlusty, J. Modern construction and architecture 1(01), 39-47 (2016)

22. A.L. Gelfond, E.A. Akhmedov, J. Architecture and construction of Russia 7, 1-2 (2015)

23. I. I. Sokolov, N.V. Ivanova, A.I. Sokolov, J. Messenger of VOLGGASU 62-63 (2008)

24. E.N. Guseva J. Messenger of VOLGGASU 47 (66), 445-455 (2017)

25. A.E. Enin, S.N. Guryev, S.A. Sukocheva, J. Architectural researches 1(13) (2018)

26. N.V. Ivanova, N.V. Sirenko, J. Great rivers Nizhny Novgorod 1, 209-212 (2017) 
27. A.V. Gorodkov, S.I. Saltanov, J. Ecology of the visual environment 192 (2013)

28. N.V. Ivanova, O.A. Ganzha, EMMFT 2 IOP Conf. Series: Earth and Environmental Science 90, 6 (2017) Doi:10.1088/1755-1315/90/1/012130

29. N.V. Fomina, http://os.x-pdf.ru/20ekonomika/673701-1-udk-9112-556537osobennosti-landshaftno-ekologicheskogo-analiza-pri.php

30. N. Ivanova, O. Ganzha, V. Prokopenko, MATEC Web of Conferences 170, 04012 (2018)

31. N.V. Ivanova, N.N. Antonova, J. International research magazine 5(47),112-114 (2016)

32. N.V. Ivanova, J. New ideas of new century TOGA 2, 114-12 (2016)

33. N. Ivanova, O. Ganzha, Procedia Engineering 165, 1006-1015 (2016) 